\title{
Ocular hypotensive effect, preservation of visual fields, and safety of adding dorzolamide to prostaglandin therapy for twelve months
}

This article was published in the following Dove Press journal:

Clinical Ophthalmology

2I March 20I I

Number of times this article has been viewed

\author{
Kenji Inoue ${ }^{1,3}$ \\ Mieko Masumoto',3 \\ Masato Wakakura' \\ Goji Tomita ${ }^{2}$ \\ On behalf of the \\ Ochanomizu Ophthalmology \\ Study Group ${ }^{3}$ \\ 'Inouye Eye Hospital, Tokyo, Japan; \\ ${ }^{2}$ Department of Ophthalmology, \\ Toho University School of Medicine, \\ Tokyo, Japan; ${ }^{3}$ Ochanomizu \\ Ophthalmology, Tokyo, Japan
}

Purpose: To prospectively evaluate the safety, hypotensive effect, and preservation of visual fields of dorzolamide when added to latanoprost.

Subjects and methods: This study included 46 patients (46 eyes) with primary open-angle glaucoma who had been treated with latanoprost. Dorzolamide (1\%) was added to latanoprost, and the intraocular pressure (IOP) was monitored before and after 3, 6, and 12 months. The mean deviation shown by Humphrey perimetry was compared before and after twelve months of treatment. Adverse reactions were monitored over the 12-month study period.

Results: The mean baseline IOP was $17.2 \pm 3.0 \mathrm{mmHg}$ while those after 3, 6 and 12 months of treatment were $14.9 \pm 3.0 \mathrm{mmHg}, 14.5 \pm 3.2 \mathrm{mmHg}$, and $14.6 \pm 2.6 \mathrm{mmHg}$ respectively $(P<0.0001,1-\beta$ (power $)=0.9999571)$. The absolute reduction of IOP and the percent reduction were similar after 3,6 , and 12 months of treatment. The mean deviation on Humphrey perimetry was similar before and after twelve months of treatment. Three patients discontinued dorzolamide therapy due to elevation of IOP and one patient discontinued it because of adverse reactions.

Conclusion: Dorzolamide is safe and effective when used for twelve months as add-on therapy to latanoprost for open-angle glaucoma.

Keywords: dorzolamide, primary open-angle glaucoma, latanoprost

\section{Introduction}

Prostaglandin analog acts by enhancing the uveoscleral outflow and lowering the intraocular pressure (IOP). The significant effect on reducing IOP and the convenience of once daily administration made Prostaglandin analog eye drops the first line therapy for glaucoma for many ophthalmologists. ${ }^{1}$ If the reduction of IOP is insufficient, however, switching therapy or adding a new agent is needed. ${ }^{2} \beta$-blockers or carbonic anhydrase inhibitors that inhibit aqueous humor production may be considered as second-line agents to be added on, since they have different mechanisms of reducing IOP to prostaglandin analog. Use of $\beta$-blockers in Japan started about 40 years ago when timolol maleate eye drops became available. As for carbonic anhydrase inhibitors, dorzolamide $(0.5 \%$ and $1 \%)$ was introduced in 1999 and brinzolamide (1\%) was released in 2002.3-5 It has been reported that the effect of $\beta$-blockers and carbonic anhydrase inhibitors on IOP is comparable, when added to prostaglandin analog therapy. ${ }^{5-7} \beta$-blockers can have systemic adverse effects, however, including induction of asthmatic attack, bradycardia, and depressive symptoms, making it difficult to use these medications in patients with such conditions or in the elderly whose physiological functions are impaired compared with younger individuals. In this respect, carbonic anhydrase inhibitors may have a
Inouye Eye Hospital, 4-3 Kanda-Surugadai, Chiyoda-ku, Tokyo 10I-0062, Japan

Tel +8 I03329509। I

$\mathrm{Fax}+810332950917$

Email inoue-k@fd5.so-net.ne.jp 
better safety profile with fewer systemic adverse effects when added to prostaglandin analog therapy.

In previous studies on the IOP-lowering effect of dorzolamide when added to prostaglandin analog therapy, the percent reduction of IOP was reported to be $6.3 \%-24.0 \%{ }^{4-11}$ Because dorzolamide is used as a $2 \%$ formulation in countries other than Japan, ${ }^{6-10}$ only a few reports have studied the $1 \%$ formulation that is available there. ${ }^{3-5,11}$ In addition, the duration of treatment in those studies was short (four weeks, ${ }^{4}$ three months, ${ }^{5}$ and six months ${ }^{11}$ ).

We previously reported on the IOP-lowering effect and safety of $1 \%$ dorzolamide when added to a prostaglandin analog for six months in patients with primary open-angle glaucoma. ${ }^{11}$ In the present study, the observation period was extended to twelve months and the effect of dorzolamide on preservation of the visual fields was also evaluated.

\section{Subjects and methods}

This was a prospective, multicenter open-label study. The study included 46 patients ( 22 men and 24 women) with 46 eyes being treated for primary open-angle glaucoma. They were on treatment with latanoprost alone, and dorzolamide was added during the period between June 2008 and May 2009 at Inouye Eye Hospital or 13 other participating institutions. The mean age \pm Standard Deviation (SD) (range) of the patients was $69.5 \pm 10.5$ years (range: $43-87$ years). The cases with the mean deviation (MD) value of $-24.00 \mathrm{~dB}$ and below were excluded from the study. The MD obtained by Humphrey perimetry was $-9.0 \pm 5.6 \mathrm{~dB}(-20.05$ to $-0.63 \mathrm{~dB})$ at baseline and the baseline IOP was $17.2 \pm 3.0$ (12 to 25$) \mathrm{mmHg}$. The spherical equivalent was $-0.5 \pm 3.9$ $(+3.25$ to -12.5$) \mathrm{D}$.

In patients with glaucoma affecting both eyes, the eye with the higher IOP was evaluated. If both eyes had the same IOP, the right eye was evaluated.

When the chief physician judged an intraocular pressure drop effect was insufficient, once-daily administration (at night) of latanoprost was continued and 1\% dorzolamide (three times daily [tid], morning, noon and night) was added. The IOP was measured by Goldmann applanation tonometry by the same observer at approximately the same time of day in each patient at baseline and every one to two months after starting the administration of dorzolamide. The baseline IOP was compared with that after 3, 6, and 12 months by analysis of variance (ANOVA) with the Bonferroni/Dunnett tests. The reduction of IOP and the percent decrease of IOP relative to baseline after 3, 6, and 12 months were calculated and compared with Friedman's test. The Humphrey C-30-2 Swedish
Interactive Threshold Algorithm (SITA) Standard program was performed at baseline and after twelve months, and the MD values were compared by the paired $t$-test. Reliability visual field test results $<20 \%$ fixation errors, $<33 \%$ falsepositive results, and $<33 \%$ false-negative results. Adverse reactions were evaluated at every visit to hospital. Patients who did not present to hospital for follow-up, who discontinued dorzolamide treatment, who started a new agent, or who underwent surgery during the 12-month study period were excluded from analysis of the IOP data. Differences were considered statistically significant at $P<0.05$ for all comparisons. The present study was approved by the ethical committee of Inouye Eye Hospital. The purpose and procedures of the study were explained to the patients and written informed consent was obtained from each subject.

\section{Results}

Compared with the baseline IOP $(17.2 \pm 3.0 \mathrm{mmHg})$, there was a significant decrease after 3,6 , and 12 months $(14.9 \pm 3.0 \mathrm{mmHg}, 14.5 \pm 3.2 \mathrm{mmHg}$, and $14.6 \pm 2.6 \mathrm{mmHg}$, respectively) in the 46 subjects $(P<0.0001,1-\beta$ (power) $=0.9999571)$ (Figure 1).

The absolute reduction of IOP was similar after 3 , 6, and 12 months $(2.4 \pm 2.5 \mathrm{mmHg}, 2.7 \pm 2.4 \mathrm{mmHg}$, $2.7 \pm 2.6 \mathrm{mmHg}$, respectively). Likewise, the percent reduction of IOP was similar after 3,6 , and 12 months $(13.0 \pm 13.4 \%, 15.1 \pm 13.5 \%, 14.6 \pm 12.4 \%$, respectively)

There was no difference of the MD obtained by Humphrey perimetry at baseline and after 12 months of treatment $(-9.0 \pm 5.6 \mathrm{~dB}$ and $-9.3 \pm 5.5 \mathrm{~dB}$, respectively) (Figure 2).

During the 12-month period of dorzolamide administration, eleven patients $(23.9 \%)$ dropped out of the study. Three patients were lost to follow-up, one patient moved and switched to another hospital, one patient suffered from adverse effects (ocular irritation), three patients did not achieve a sufficient reduction of IOP, one patient died of an

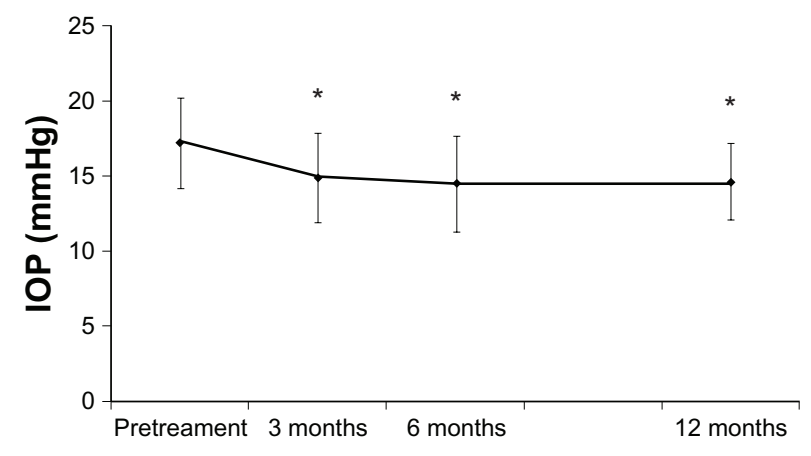

Figure I Intraocular pressure (IOP) before and after addition of dorzolamide. Notes: $* P<0.0001$, ANOVA and the Bonferroni/Dunnett tests. 


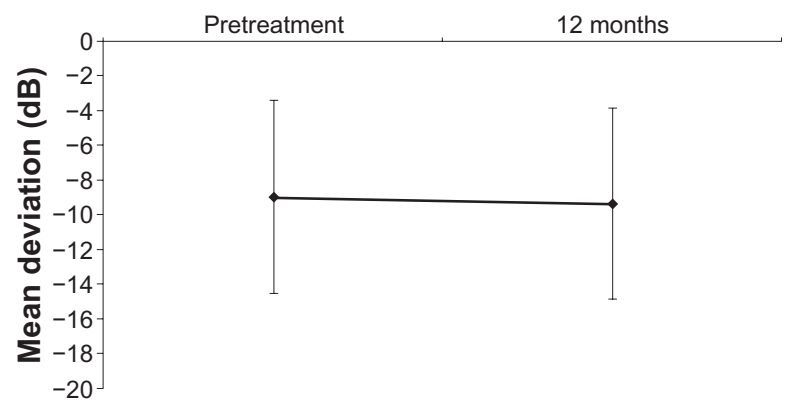

Figure 2 Mean deviation at baseline and 12 months after addition of dorzolamide. Note: Paired $t$-test.

Abbreviation: NS, not significant.

unrelated disease, one patient underwent surgery for another disease, and one patient was enrolled in another study. The adverse effects observed in one patient resolved after discontinuation of dorzolamide. Of the three patients who did not achieve a sufficient reduction of IOP, one patient increased IOP from $18 \mathrm{mmHg}$ at baseline to $22 \mathrm{mmHg}$ after two months and one patient increased IOP from $13 \mathrm{mmHg}$ at baseline to $14 \mathrm{mmHg}$ after five months. In these two patients, dorzolamide was switched to a $\beta$-blocker. In the third patient, IOP increased from $19 \mathrm{mmHg}$ at baseline to $22 \mathrm{mmHg}$ after three months and glaucoma surgery was performed.

\section{Discussion}

Several studies have demonstrated that IOP is reduced when dorzolamide is added to basal prostaglandin analog therapy ${ }^{4-11}$ (Table 1).

In Japan, $0.5 \%$ and $1 \%$ formulations of dorzolamide are used, but only three studies have evaluated the effect of these formulations when added to basal prostaglandin ana$\log$ therapy. ${ }^{4,5,11}$ In the study by Maruyama and Shirato, $1 \%$ dorzolamide (tid) was added for three months following three months of monotherapy with latanoprost in 33 patients with primary open-angle glaucoma. ${ }^{5}$ IOP decreased significantly from baseline $(16.0 \pm 2.1 \mathrm{mmHg})$, with an absolute reduction and percent reduction of $1.0 \mathrm{mmHg}$ and $6.3 \%$, respectively. In addition, Nakamura et al added 1\% dorzolamide (twice daily [bid] or tid) for four weeks in 20 patients with primary open-angle glaucoma, ocular hypertension, or angle-closure glaucoma after laser peripheral iridotomy who had been treated with latanoprost alone, but still had an IOP $\geq 18 \mathrm{mmHg}{ }^{4}$ Measurement of the circadian changes of IOP showed a significant decrease from baseline $(20.0 \mathrm{mmHg}$ ) at all time points, with the absolute reduction and percent reduction being 2.4 to $4.8 \mathrm{mmHg}$ and 12.0 to $24.0 \%$, respectively. In our previous study, $1 \%$ dorzolamide (tid) was added to latanoprost or travoprost for six months in 55 patients with primary open-angle glaucoma. ${ }^{11}$ The IOP decreased significantly from baseline $(16.7 \pm 2.4 \mathrm{mmHg})$, and showed an absolute reduction and percent reduction of 2.5 to $2.8 \mathrm{mmHg}$ and 14.2 to $16.4 \%$, respectively. In the present study, $1 \%$ dorzolamide (tid) was added to latanoprost for twelve months in 46 patients with primary open-angle glaucoma. We found that the IOP decreased significantly from baseline $(17.2 \pm 3.0 \mathrm{mmHg})$, with the absolute reduction and percent reduction being 2.4 to $2.7 \mathrm{mmHg}$ and 13.0 to $15.1 \%$, respectively. These results were consistent with those reported previously. ${ }^{4-11}$ However, the present study was conducted in an open-label manner, so the IOP-lowering effect of dorzolamide may have been overrated. When the percent reduction of IOP was compared between different formulations of dorzolamide, the IOP lowering effect of the $2 \%$ formulation $(12.5 \%-20.6 \%)^{6-10}$ and the $1 \%$ formulation $(6.3 \%-24.0 \%)^{4,5,11}$ seemed to be similar.

No previous study has evaluated the effect of dorzolamide on preservation of the visual fields when added to basal prostaglandin analog therapy, possibly because the duration

Table I Review of previous studies conducted outside/inside Japan

\begin{tabular}{|c|c|c|c|c|c|c|c|}
\hline & $\begin{array}{l}\text { Previous } \\
\text { eye drops }\end{array}$ & Dorzolamide & $\begin{array}{l}\text { Number } \\
\text { of cases }\end{array}$ & Duration & $\begin{array}{l}\text { Baseline IOP } \\
(\mathrm{mmHg})\end{array}$ & $\begin{array}{l}\text { Absolute } \\
\text { reduction }(\mathrm{mmHg})\end{array}$ & $\begin{array}{l}\text { Percent } \\
\text { reduction (\%) }\end{array}$ \\
\hline O'Connor 6 & Latanoprost & $2 \%$ (bid or tid) & 25 & I year & 19.8 & 3.9 & 19.7 \\
\hline Tamer $^{7}$ & Latanoprost & $2 \%$ (bid) & 36 & 4 weeks & 19.9-23.3 & $2.6-3.2$ & $12.5-14.7$ \\
\hline \multirow[t]{3}{*}{ Bournias $^{8}$} & Latanoprost & $2 \%($ tid) & 40 & 4 months & $20.3-21.9$ & $2.8-3.4$ & $13.3-15.5$ \\
\hline & Travoprost & & & & & & \\
\hline & Bimatoprost & & & & & & \\
\hline Boyer 9 & Travoprost & $2 \%$ (bid) & 86 & 6 months & $18.9 \pm 4.2$ & 3.9 & 20.6 \\
\hline Arici ${ }^{10}$ & Latanoprost & $2 \%($ tid) & 15 & 10 days & $18.7 \pm 2.3$ & 2.8 & 15.0 \\
\hline Maruyama $^{5}$ & Latanoprost & I\% (tid) & 33 & 3 months & $16.0 \pm 2.1$ & 1.0 & 6.3 \\
\hline Nakamura $^{4}$ & Latanopropt & I\% (bid or tid) & 20 & 4 weeks & 20.0 & $2.4-4.8$ & $12.0-24.0$ \\
\hline Inoue & $\begin{array}{l}\text { Latanoprost } \\
\text { Travoprost }\end{array}$ & $1 \%$ & 55 & 6 months & $16.7 \pm 2.4$ & $2.5-2.8$ & $14.2-16.4$ \\
\hline
\end{tabular}

Abbreviations: bid, twice daily; tid, three times daily; IOP, intraocular pressure. 
of combined treatment with dorzolamide was short in most studies. In a previous 1-year study, the effect of dorzolamide on the visual fields was not assessed because the study was conducted retrospectively. ${ }^{6}$ In the present study, the MD obtained by Humphrey perimetry did not change after addition of dorzolamide for 12 months, indicating a positive effect of dorzolamide therapy on preservation of the visual fields. However, the treatment period was only twelve months, so further studies over a longer period are needed.

When dorzolamide is used with a prostaglandin analog, the reported adverse effects include hyperemia, irritation, foreign body sensation, blurred vision, corneal epithelial disorder, and dysgeusia. ${ }^{4,5,7,8,10}$ In several previous studies, no serious adverse effects were observed, ${ }^{4,5,7-11}$ which is consistent with the present results. In the present study, sufficient reduction of IOP was not achieved by combined therapy in three patients, suggesting that there is a group of non-responders to dorzolamide.

\section{Conclusion}

Dorzolamide had a potent IOP-lowering effect as well as a positive effect on preservation of the visual fields in patients with primary open-angle glaucoma when added to latanoprost for twelve months. However, it remains unclear whether these effects are caused by adding dorzolamide or they can be gained by latanoprost only, or they are synergetic effects of both dorzolamide and latanoprost. It also had a good safety profile and did not cause any serious adverse effects. Thus, the $1 \%$ dorzolamide has enough IOP-lowering effect and it may be a useful second-line agent after latanoprost for the treatment of glaucoma.

\section{Acknowledgment}

This study was supported by a grant from the Advancement of International Science Foundation.

The following members of the Ochanomizu Ophthalmology Study Group participated in this study.

Ishii Eye Clinic - Yasuhiro Ishii; Ueda Eye Clinic - Hiroko Ueda; Kinugawa Eye Clinic - Yuichi Kinugawa; Goto Eye
Clinic - Katsuhiro Goto; Nakai Eye Clinic - Masaki Nakai; Nakai Eye Center - Yoshiyuki Nakai; Fujita Eye Clinic Natsuya Fujita; Ezure Eye Clinic - Tsukasa Ezure; Nakamura Clinic - Satoshi Nakamura; Shamoto Eye Clinic - Maki Shamoto; Hashida Eye Clinic - Setsuko Hashida; Yanagawa Ophthalmologic Clinic - Takashi Yanagawa; Nishikasai Inouye Eye Hospital - Yasushi Nozaki, Kentaro Shimizu, ShoichiSoeda, Mieko Tsuruoka, and Norie Nozaki; Inouye Eye Hospital - Minako Shiokawa, Risako Higa, Ryo Moriyama, and Hideko Sawada.

\section{Disclosure}

The authors report no conflicts of interest in this work.

\section{References}

1. Van der Valk R, Webers CA, Jan SA, et al. Intraocular pressure-lowering effects of all commonly used glaucoma drugs. Ophthalmology. 2005; 112:1177-1185

2. Araie M, Abe H. The Japan Glaucoma Society Guidelines for Glaucoma, 2nd ed. Jpn J Ophthalmol Soc. 2006;110:777-814.

3. Araie M, Kitazawa Y, Azuma I, et al. The efficacy and safety of dose escalation of dorzolamide used in combination with other topical antiglaucoma agents. J Ocul Pharmacol Ther. 2003;19:517-525.

4. Nakamura Y, Ishikawa S, Nakamura Y, et al. 24-hour intraocular pressure in glaucoma patients randomized to receive dorzolamide or brinzolamide in combination with latanoprost. Clin Ophthalmol. 2009; 3:395-400.

5. Maruyama K, Shirato S. Additive effect of dorzolamide or carteolol to latanoprost in primary open-angle glaucoma. A prospective randomized crossover trial. J Glaucoma. 2006;15:341-345.

6. O'Connor DJ, Martone JF, Mead A. Additive intraocular pressure lowering effect of various medications with latanoprost. Am J Ophthalmol. 2002;133:836-837.

7. Tamer C, Öksüz H. Circadian intraocular pressure control with dorzolamide versus timolol maleate add-on treatments in primary openangle glaucoma patients using latanoprost. Ophthalmic Res. 2007; 39:24-31.

8. Bournias TE, Lai J. Brimonidinetartate $0.15 \%$, dorzolamide hydrochloride $2 \%$, and brinzolamide $1 \%$ compared as adjunctive therapy to prostaglandin analogs. Ophthalmology. 2009;116:1719-1724.

9. Boyer S, Gay D. Additive effect of dorzolamide hydrochloride to patients taking travoprost: A retrospective study. Optometry. 2008;79: 501-504.

10. Arici MK, Topalkara A, Guler C. Additive effect of latanoprost and dorzolamide in patients with elevated intraocular pressure. Inter Ophthalmol. 1998;22:37-42.

11. Inoue K, Wakakura M, Kinugawa Y, et al. Short-term hypotensive effect of dorzolamide added to prostaglandin-related topical medication. Jpn J Clin Ophthalmol. 2010;64:725-728.
Clinical Ophthalmology

\section{Publish your work in this journal}

Clinical Ophthalmology is an international, peer-reviewed journal covering all subspecialties within ophthalmology. Key topics include: Optometry; Visual science; Pharmacology and drug therapy in eye diseases; Basic Sciences; Primary and Secondary eye care; Patient Safety and Quality of Care Improvements. This journal is indexed on

\section{Dovepress}

PubMed Central and CAS, and is the official journal of The Society of Clinical Ophthalmology (SCO). The manuscript management system is completely online and includes a very quick and fair peer-review system, which is all easy to use. Visit http://www.dovepress.com/ testimonials.php to read real quotes from published authors. 